\title{
Sachs, meu mestre
}

Cristovam Buarque

$\mathrm{E}$ M 1975, enviei uma volumosa biografia de Michal Kalecki para Ignacy Sachs. Sabia da importância do economista polonês na formação dele, mas precisei esperar mais de trinta anos para saber a real dimensão dessa influência, ao ler o capítulo nove do livro $A$ terceira margem de Sachs, cujo título é "Kalecki, meu mestre".

Kalecki foi um gênio que, em 1930, teve a ousadia de enviar ao diretor do Instituto de Estudos sobre Conjuntura Econômica da Polônia um pequeno trabalho, sugerindo o caminho para retirar o país da depressão de 1930. Escreveu: "Solicito encontrar anexo um memorando no qual proponho cenários que permitiriam tirar a Polônia da crise atual". Ele era um estudante do terceiro ano de engenharia. Por incrível que possa parecer, esse pequeno trabalho, de um jovem de vinte anos, antecipou-se ao que depois escreveria o próprio grande John Maynard Keynes. Kalecki retirava o pensamento econômico da visão do padrão ouro e da repulsão ao Estado, para o entendimento da importância do investimento estatal na economia. Trinta anos depois dessa revolução intelectual, Sachs conviveu com Kalecki, em Varsóvia, e foi seu discípulo.

$\mathrm{O}$ mesmo aconteceu comigo, em relação a Sachs. Só não sabia que a influência tinha sido tão grande, até ler a autobiografia de Sachs e perceber o quanto minhas ideias, concepções e até comportamento intelectual decorrem da minha convivência com ele. Ao ver a exposição retrospectiva que ele faz de seu trabalho, descobri onde me inspirei quase totalmente na maneira de ver a economia, nas propostas que concebi e executei como professor, consultor e político.

Lembro-me do nosso primeiro encontro, na terceira semana de outubro de 1970, em seu gabinete de professor na École des Hautes Études Sociales, da Universidade de Paris, Sorbonne. Fui levado por meu amigo Jesus Camara $\mathrm{Za}$ pata. Sachs tinha 43 anos, estava sentado em seu escritório, rodeado de livros, segurando um cachimbo. Carregava o passado cosmopolita de judeu-polonês, crescido e graduado no Brasil, técnico de nível superior no governo socialista da Polônia, com doutorado em Nova Delhi, na Índia, e professor na Universidade de Paris. Eu tinha 26 anos, nordestino, tendo sempre vivido em Recife, com simpatia pelo pensamento marxista e uma boa carga de leitura para os padrões brasileiros, mas um semialfabetizado intelectual, se comparado aos padrões europeus.

Ele tinha menos de três anos de $\mathrm{Pa}$ ris, eu tinha cinco dias, Zapata dois anos. Tinha ido para fazer um doutorado que me transformasse de engenheiro mecânico em economista, e tinha bolsa do governo francês, mas para ser aceito e fazer minha inscrição na universidade precisava de um professor que me acolhesse como orientador. Sachs orientava Zapata, que foi o seu primeiro aluno a defender tese em Paris.

Depois da rápida apresentação, Sachs me perguntou sobre o tema que eu desejava trabalhar na minha tese de doutorado. Com a arrogância de quem tinha 26 anos, disse que queria fazer uma tese sobre a "Teoria do Valor", o tema central de toda grande obra de economista. 
Com seu cachimbo na mão, ele apontou ao redor nas estantes e disse: "Daqui a vinte anos você não terá escrito nada que já não esteja em um desses livros, escrito por centenas de velhos economistas depois de décadas de pesquisas e reflexões. Se você escrever sobre o Nordeste brasileiro, em poucos anos de pesquisa vai escrever ideias que nenhum deles teve".

Ali começou a influência decisiva do Sachs. Se ele tivesse dito "tudo bem, estou aqui para isso", provavelmente até hoje eu não teria terminado a tese. Foi uma lição que sempre transfiro aos meus alunos. Durante anos, na minha sala no Departamento de Economia na UnB, mantive um cartaz com o texto "A única tese realmente ruim é a que não foi escrita".

Três anos depois, fazendo e refazendo, lendo e escrevendo, conversando com ele, às vezes andando nas ruas de $\mathrm{Pa}-$ ris enquanto ele ia de um lugar para outro, em sua intensa e variada agenda, fui sendo orientado e concluí minha tese, na linha do seu pensamento e preocupação: como o Estado intervém nas economias capitalistas, analisando o caso específico do Nordeste brasileiro com a Sudene.

Desde então, mantenho uma relação estreita e de amizade com Sachs, em sua casa em Paris ou São Paulo, em minha casa em Brasília. Nas muitas conversas, ao longo de quarenta anos, podia dizer que sabia muito de sua vida, mas a leitura de suas memórias me surpreendeu - pelos detalhes da aventura de uma vida de perseguições, reviravoltas, riscos, ganhos e perdas; pelo humor permanente, dandose ao luxo de um capítulo inteiro de anedotas sobre a vida em um país socialista; pela profundidade, pelo rigor e pela criatividade das suas ideias, na segunda metade do século XX, especialmente nas áreas do Planejamento e da Ecologia; e pela amplitude de suas andanças por toda parte, seus contatos e amizades com grandes personalidades do mundo todo.

Sua história começa como um menino nascido em uma das famílias mais ricas da Polônia, dona de banco e conglomerado de indústrias, no começo da década de 1930. Rica, sem ser da nobreza, por ser judia. Quando tinha nove anos, a família foi obrigada a deixar tudo para trás e fugir da invasão nazista que levou 1,2 milhão de judeus poloneses ao campo de concentração e à morte.

Era a primeira fuga da Polônia, ainda criança. O livro descreve a aventura por terra, com os sucessivos riscos de prisão, a sobrevivência sem dinheiro, a perda e o reencontro com o pai por pura coincidência, na porta do correio da cidade francesa, onde ele, seu irmão e a mãe estavam de passagem. São fatos emocionantes. Fato surpreendente, que mostra a diferença entre uma família judia polonesa e nós brasileiros, é quando ele diz que no dia seguinte à chegada a uma cidade no sul da França, ainda buscando refúgio, sua mãe o matriculou, e também o irmão, na escola. Recorda o recente filme $O$ leitor, em que a sobrevivente do campo de concentração diz "o analfabetismo não é uma questão do povo judeu”, porque já está resolvida.

Com a Europa tomada pelos nazistas e o antissemistismo se espalhando, a família é obrigada a seguir até o final do continente europeu, em Lisboa, e daí a tomar um navio para o Brasil, fugindo de Salazar. Pegaram o último navio a cruzar o Attântico antes de a marinha nazista começar a afundá-los.

A vida no Brasil é um capítulo delicioso, pela reconstituição do Rio e São Paulo nos anos 1940 e começo dos 1950, pelas 


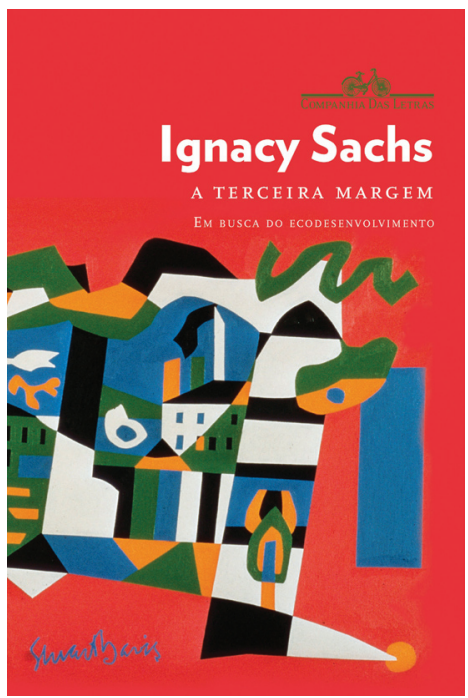

SACHS, Ignacy. A terceira margem Em busca do ecodesenvolvimento.

Trad. Rosa Freire D'Aguiar. São Paulo: Cia. das Letras, 2009. 400p.

peripécias de um garoto judeu, polonês e brasileiro. Seu trabalho na embaixada polonesa, sua convivência com artistas e intelectuais, a suspeição sobre ele por trabalhar ligado a um país do recém-fundado socialismo no Leste Europeu.

Sua volta do Rio para Varsóvia é um capítulo instigante do livro, mostrando o trabalho em um país do Leste Europeu, no início do socialismo, suas chances, as amarras sofridas pelo sistema, sua convivência com Oskar Lange e Michal Kalecki. Esse longo período, de quase treze anos, foi intercalado com a chance do doutorado na Índia. A descrição da vida na Índia também é estimulante, mostrando a riqueza intelectual e política da vida do país no início de sua independência.

Foi aí que Sachs adotou os três eixos ("As três margens do rio") de sua vida intelectual - Brasil, Índia, Polônia - com o auxílio de dezenas de personalidades com as quais conviveu. Ao longo do li- vro, que lamentavelmente não tem índice onomástico, ele cita centenas de nomes, a lista da inteligência da economia do desenvolvimento nos anos 1950 até os dias de hoje.

A segunda saída da Polônia, em 1968, é outra grande aventura, concluída com sua cadeira na École des Hautes Études en Sciences Sociales, onde o encontrei em outubro de 1970. Dessa vez, não foram os invasores nazistas, mas os próprios socialistas compatriotas que tornaram sua vida impossível.

A partir daí, A terceira margem é o livro das andanças, por todo o mundo, de um pragmático D. Quixote na luta pelo "bom desenvolvimento", contra o "mau desenvolvimento", na procura da convivência entre natureza e seres humanos, entre planejamento e democracia, entre grande industrialização e pequenas soluções, e na defesa das economias nacionais com integração internacional.

Sachs mostra que é um homem cosmopolita, heterodoxo, sem preconceitos e com firmes conceitos e princípios. Ele dedica os últimos capítulos a mostrar suas ideias como acadêmico, e suas propostas como consultor, pelas quais lutou mundo afora, nem sempre conseguindo executar o que "cochichava ao ouvido de príncipes". Chega a dedicar um capítulo - e diz que poderia escrever um livro inteiro - às "derrotas" de suas ideias.

É nelas, porém, que me vi como seu discípulo. Nos meus cursos, como professor; na reforma universitária que fiz como reitor; nos projetos que implantei como governador; e no meu programa como candidato a presidente da República; sempre tive por base as lições de Sachs.

A visão da universidade como espaço do conhecimento multidisciplinar que 
implantei na UnB, a procura de fazê-la conviver com o mundo real são exemplos dos ensinamentos que recebi dele. As dezenas de programas implantados no governo do Distrito Federal, todos eles buscando o "bom desenvolvimento", o crescimento pela base, a convivência entre a globalização e o local, a execução de soluções simples, o emprego útil dos desempregados em atividades de seus próprios interesses, o respeito à natureza, a busca de unir mais de um problema na busca de uma solução, tudo isso estava explícito no pensamento que Sachs transmitia aos seus alunos, e que eu tive a sorte de captar.

Além disso, como mestre, ele não só dava resposta, ele nos ajudava a ver o mundo mudando a óptica com que olhávamos o mundo. Tornou-me heterodoxo, livre dos preconceitos teóricos e, sempre preso aos princípios, trouxe-me uma visão cosmopolita sem perder o apego ao local, ampliou o horizonte de interesses culturais, mostrando que o pensamento não se faz com uma disciplina profissional.

Ninguém pode ser economista sério sem uma extensa leitura de filosofia, história, literatura, especulações, ensaios sobre todos os temas, sem exceção, e até muita leitura de biografias, como $A$ terceira margem, que me fez arqueólogo de minhas "próprias" ideias nascidas do convívio com professores, amigos, alunos e especialmente uns poucos aos quais chamamos de mestre, como Sachs.

Se ele teve essa influência na minha atividade de formulador e executor de políticas públicas, ainda mais nas ideias que coloquei nos livros. Não consigo imaginar ter escrito $A$ desordem do progresso e seus três complementos, além de A segunda abolição, A cortina de ouro e, especialmente, $O$ admirável mundo atual, sem - mais do que o ensinamento a inspiração que dele recebi, para nunca olhar as coisas e os problemas a partir de ópticas predeterminadas.

É preciso reorientar sempre o olhar, inclusive em relação aos mestres. Por isso, meu ponto de autonomia em relação ao pensamento dele: a ênfase na educação como vetor do progresso.

A terceira margem não dedica espaço ao tema educação. Salvo quando fala da sua própria educação quando criança, ou quando toca no assunto da formação de quadros técnicos para o desenvolvimento econômico - que ele mostra ter tido certo desperdício, por causada migração de cérebros dos países pobres para os países ricos.

Mas mesmo essa minha visão diferente é uma homenagem à educação que ele me deu, como meu mestre, ao incentivarme a mudar a maneira de ver o mundo, de entender os problemas, de buscar novos paradigmas. Como o Educacionismo, que eu concebi e comecei a formular, ainda sem perceber, naquele outubro de 1970 em que tive a sorte de encontrar Sachs, meu mestre.

Cristovam Buarque é professor da Universidade de Brasília (UnB) e senador pelo PDT-DF.

@ - cristovam@senado.gov.br

Texto elaborado na ocasião do lançamento do livro A terceira margem - Em busca do ecodesenvolvimento, em Brasília-DF, em 22.10.2009. 